\title{
Beckmann Rearrangement of 3-carboxybicyclo[3.3.1]nonane and [3.2.1]octane Oximes
}

\author{
Andriy S. Bulochnikov, Olga O. Ryzhenko, Marian V. Gorichko* \\ Department of Chemistry, Taras Shevchenko National University of Kyiv, Volodymyrska Street, \\ 64/13, Kyiv 01601, Ukraine \\ gorichko@,chem.univ.kiev.ua
}

Keywords: Beckmann rearrangement, oxime, bicyclo[3.3.1] nonane, bicyclo[3.2.1] octane, lactam Regiospecific Beckmann rearrangement of substituted 2-hydroximinonorbornanone carboxylic acids has been investigated. Selective formation of new functionalized 10-oxo-9azabicyclo[3.3.2]decanes and 7-oxo-6-azabicyclo[3.2.2]nonanes in good yield has been demonstrated. Presence of neighboring carboxylic group allows conducting of Beckmann rearrangement of strained bicyclic compounds.

\section{Introduction}

Beckmann rearrangement, discovered 130 years ago, has been widely used for the purposes of modern organic synthesis of large variety of natural products, pharmaceuticals and products of bulk industrial processes [1-3]. Nevertheless strained cyclic systems undergo abnormal rearrangement (Beckmann fragmentation) which is often accomplished with different carbocation rearrangements resulting in complex mixture of products [4-10]. Thus norbornanone oximes, among them the most available and as a consequence the most investigated are terpenoid derivatives, showed very poor ability to form classic rearrangement products. Camphor oxime can give up to 12 products under different reaction conditions, but no formation of desired lactame was observed [11]. Substituted norbornanone oximes have been reported to form a mixture of fragmentation products under various acidic, basic and photochemical conditions. Bicyclic lactames were detected as minor byproducts only in a few cases [12-15].

\section{Results and discussion}

We have chosen two pairs of model substrates in order to examine the assumption, that carboxyl group in proper position can be involved in Beckmann rearrangement by influencing on its products or on the kinetics of the rearrangement. In our studies we investigated anti- and syn-8oximinobicyclo[3.2.1]octane- and 9oximinobicyclo[3.3.1] nonane-3-carboxylic acids $(1.1,1.2,2.1,2.2)$ (Figure 1). 


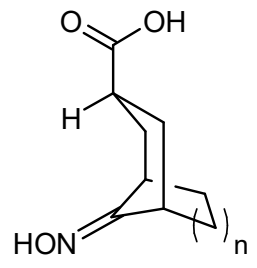

$1.1(n=1)$

$2.1(n=2)$

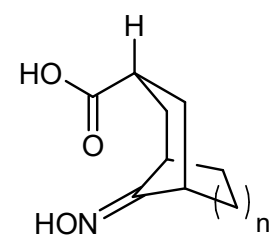

$1.2(n=1)$

$2.2(n=2)$
Figure 1. Bicyclic oximinocarboxylic acids.

\section{Compounds $\mathbf{1 . 1}$ and 2.1 contain} significantly distant carboxyl group, which probably does not affect the reaction behavior. In turn, compounds $\mathbf{1 . 2}$ and $\mathbf{2 . 2}$ have close carboxyl group, which is probably able to stabilize the transition state of the Beckman rearrangement by overlapping of vacant orbitals of intermediate carbocations with the lone pairs of oxygen atoms of carboxyl groups and contribute to obtaining products of normal rearrangement or influence the reaction, resulting in recyclization or fragmentation products. In addition, it should be noted that both types of bicyclic oximes have features that allow using them as convenient model compounds. Firstly, these oximes are not able to deuterium exchange of the bridgehead $\alpha$-protons according to the Bredt's rule. This greatly facilitates rearrangement monitoring in a solution of deuterated trifluoroacetic acid. Secondly, in the case of Beckmann rearrangement regioisomeric products should not be expected due to the symmetry of the molecules, which contributes to easier identification of the reaction products.
All the oximino acids were prepared from corresponding keto acids and hydroxylamine hydrochloride in presence of pyridine. Ketoacids 3, 4, 5 and $\mathbf{6}$ were synthesized by alkylation of 1-pyrrolidino-1cyclopentene (7) or 1-pyrrolidino-1cyclohexene (8) with ethyl 3-bromo-2bromometylpropionate (9) [16-18]. As a result we obtained bicyclic esters of anti-configuration $(10,11)$ due to steric factors. These esters was subjected to hydrolysis in aqueous $\mathrm{LiOH}$ resulting anti-keto acids 3 and 4, another part of the esters 10 and 11 was isomerized in $\mathrm{MeONa}$ to syn-keto esters 12, $\mathbf{1 3}$ and then also hydrolyzed to syn-keto acids 5 and $\mathbf{6}$ (Scheme 1).

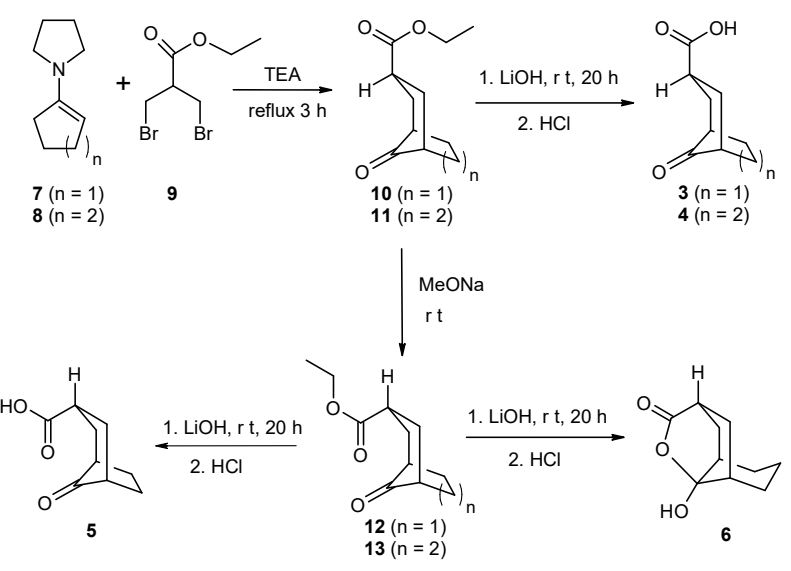

Scheme 1. Synthesis of syn- and anti-keto acids.

Spectral measurements showed differences between these acids. Syn-keto acid $\mathbf{6}$ exists in the lactole form, which shows the spatial proximity of carbonyl and carboxylic groups. In turn, anti-keto acid $\mathbf{4}$ does not have such proximity of functional groups and lactole is not formed. Despite the more electrophilic character of carbonyl group in keto acid $\mathbf{5}$ than in $\mathbf{6}$, bicyclo[3.2.1] octane-carboxylic acid $\mathbf{5}$ 
does not form lactole. This obviously indicates a greater spatial distance between carboxyl and carbonyl groups.

Beckman rearrangement was carried out by heating of oximino acids in trifluoroacetic acid (Scheme 2).
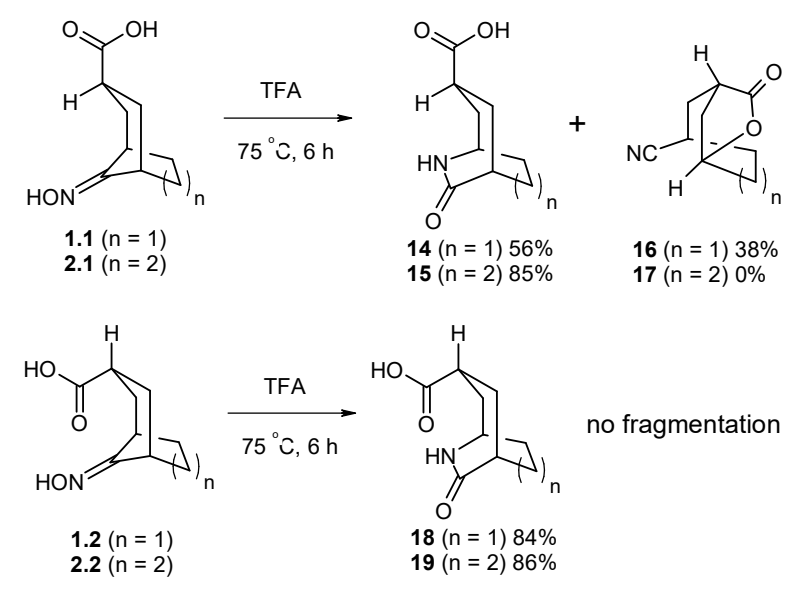

Scheme 2. Beckmann rearrangement of bicyclic oximes.

The obtained data indicate that oximes 2.1 and 2.2 in solution of trifluoroacetic acid at a temperature of $73-75{ }^{\circ} \mathrm{C}$ after 6 hours completely converted to the corresponding lactams 15 and 19. Intermediate probes in deuterated trifluoroacetic acid show that the syn-oxime 2.2 reacts slightly faster than antioxime 2.1. Conversion ratio for syn-/antioximes was 31.5/23 after $1 \mathrm{~h}$ heating and 79/68 after $3 \mathrm{~h}$ heating.

Bicyclo[3.2.1]octane oximes $\mathbf{1 . 1}$ and $\mathbf{1 . 2}$ react with the same speed, but in different directions. syn-Oxime $\mathbf{1 . 2}$ underwent classical Beckmann rearrangement forming lactam 18. However, anti-oxime $\mathbf{1 . 1}$ gave a mixture of products - lactam 14 (rearrangement product) and lactone $\mathbf{1 6}$ (recyclization product) in the ratio of 3: 2. The appearance of the lactone $\mathbf{1 6}$ could be explained by fragmentation process of oxyme 1.1 and recovering of cation by neighboring carboxyl group (Scheme 3).

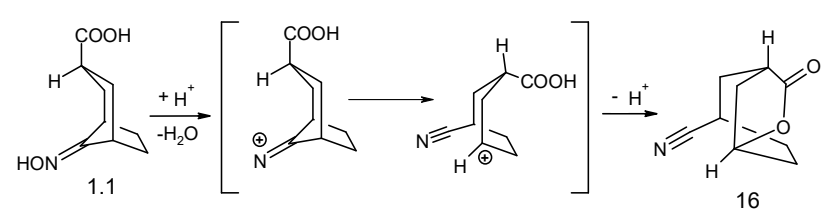

Scheme 3. Plausible mechanism of formation of lactone 16.

\section{Conclusions}

We can conclude that bicyclo[3.3.1]nonane skeleton is large enough to stabilize the 9-azabicyclo[3.3.2]decene carbocation transition state of normal Beckmann rearrangement, unlike the above mentioned bicyclo[2.2.1]heptanes. Therefore, several cationic transition states may exist, which promotes Beckmann rearrangement similar to oxime of cyclohexanone. Carboxyl group in compounds 2.1 and 2.2 does not participate significantly in the reaction, although likely contributes to more rapid progress in syn-oxime 2.2. Considering that there is no fragmentation of syn-oxime $\mathbf{1 . 2}$ it is arguable that spatially contiguous carboxyl group stabilizes the transition state, showing anchimeric assistance, promotes the formation of lactam.

\section{Experimental part}

All starting materials were purchased from Acros, Merck, Aldrich and Fluka chemicals. All solvents were distilled before use [19]. All experiments, unless otherwise stated, 
were carried under Argon atmosphere. The ${ }^{1} \mathrm{H}$ and ${ }^{13} \mathrm{C}$ NMR spectra were recorded on a "Mercury 400" Varian and Bruker AM 400 (400 $\mathrm{MHz}$ ) spectrometers. Tetramethylsilane was used as an internal standard. Mass spectra ware recorded on Agilent 1100 LSMS SL instrument with chemical ionization. Melting points are uncorrected.

General method of preparation. antiand syn-8-oximinobicyclo[3.2.1]octane- and 9oximinobicyclo[3.3.1] nonane-3-carboxylic

acids $(1.1, \quad 1.2, \quad 2.1,2.2)$. Hydroxylamine hydrochloride $(6 \mathrm{mmol})$ and pyridine $(6 \mathrm{mmol})$ was added to a stirred solution of $5 \mathrm{mmol}$ of keto acid (compounds 3-6) in 2-propanol. The reaction mixture was heated under reflux for 5 h. After that, the reaction was evaporated under reduced pressure and $100 \mathrm{ml}$ of distilled water was added to the residue. The product was filtered, washed with water, dried and recrystallized from methanol to give compounds

\section{$1.1,1.2,2.1,2.2$}

anti-8-oximinobicyclo[3.2.1] octane-3carboxylic acid (1.1). Yield of $88 \%$, a white

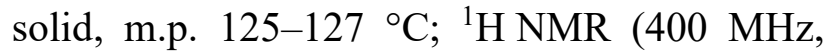
DMSO-d ${ }_{6}$ ): $\delta=12.35$ (br s, $\left.1 \mathrm{H}, \mathrm{COOH}\right), 10.00$ (br s, 1H, N-OH), $3.13(\mathrm{~s}, 1 \mathrm{H}), 2.59-2.51(\mathrm{~m}$, $1 \mathrm{H}), 2.50-2.41(\mathrm{~m}, 2 \mathrm{H}), 2.39-2.33(\mathrm{~m}, 1 \mathrm{H})$, 1.90-1.79 (m, 1H), 1.66-1.53 (m, 4H). ${ }^{13} \mathrm{C}$ NMR $\left(125 \mathrm{MHz}, \mathrm{DMSO}-\mathrm{d}_{6}\right): \delta=176.98,167.23$, $37.36,35.83,34.14,33.42,31.63,24.17,24.16$.
Anal. calcd. for $\mathrm{C}_{9} \mathrm{H}_{13} \mathrm{NO}_{3}: \mathrm{C}, 59.00 ; \mathrm{H}, 7.15$; N, 7.65. Found: C, 58.89; H, 7.24; N, 7.59.

syn-8-oximinobicyclo[3.2.1] octane-3-carboxylic acid (1.2). Yield of $93 \%$, a white solid, m.p. 135-138 ${ }^{\circ} \mathrm{C} ;{ }^{1} \mathrm{H}$ NMR (400 MHz, DMSO-d 6 ): $\delta=12.15($ br s, $1 \mathrm{H}, \mathrm{COOH}), 10.07$ (br s, $1 \mathrm{H}, \mathrm{N}-$ $\mathrm{OH}$ ), 3.18 (br s, 1H), 2.74 (pent, 1H, $J=7.4$ $\mathrm{Hz}), 2.52$ (s, 1H), 1.96-1.92 (m, 1H), 1.85-1.82 (m, 1H), 1.67-1.59 (m, 6H). ${ }^{13} \mathrm{C}$ NMR (125 MHz, DMSO-d 6 ): $\delta=176.17,166.86,38.13$, 37.46, 35.42, 34.14, 31.61, 25.27, 25.12. Anal. calcd. for $\mathrm{C}_{9} \mathrm{H}_{13} \mathrm{NO}_{3}$ : C, 59.00; H, 7.15; N, 7.65. Found: C, 58.86; H, 7.25; N, 7.57.

anti-9-oximinobicyclo[3.3.1] nonane-3carboxylic acid (2.1). Yield of $89 \%$, a white solid, m.p. $185-187{ }^{\circ} \mathrm{C}$; ${ }^{1} \mathrm{H}$ NMR (400 MHz, DMSO-d 6 ): $\delta=11.87$ (br s, $1 \mathrm{H}, \mathrm{COOH}), 9.95$ (br s, 1H, N-OH), $3.54(\mathrm{~d}, J=10.8 \mathrm{~Hz}, 1 \mathrm{H})$, $2.52(\mathrm{t}, J=7.8 \mathrm{~Hz}, 1 \mathrm{H}), 2.20-2.08(\mathrm{~m}, 2 \mathrm{H})$, 2.04-1.97 (m, 1H), 1.92-1.86 (m, 1H), 1.711.59 (m, 4H), $1.54-1.42$ (m, 3H). ${ }^{13} \mathrm{C} \mathrm{NMR}$ (125 MHz, DMSO-d $): \delta=176.08,161.96$, $37.31,34.29,33.25,32.25,30.76,30.05,25.66$, 15.19. Anal. calcd. for $\mathrm{C}_{10} \mathrm{H}_{15} \mathrm{NO}_{3}: \mathrm{C}, 60.90 ; \mathrm{H}$, 7.67; N, 7.10. Found: C, 60.82; H, 7.76; N, 7.01 .

syn-9-oximinobicyclo[3.3.1]nonane-3carboxylic acid (2.2). Yield of $91 \%$, a white solid, m.p. $176-179{ }^{\circ} \mathrm{C}$; ${ }^{1} \mathrm{H}$ NMR (400 MHz, DMSO-d $\left.{ }_{6}\right): \delta=12.16$ (br s, $\left.1 \mathrm{H}, \mathrm{COOH}\right), 10.14$ 
(br s, 1H, N-OH), 3.44 (s, 1H), 3.15 (pent, $J=$ $7.8 \mathrm{~Hz}, 1 \mathrm{H}), 2.42(\mathrm{~s}, 1 \mathrm{H}), 2.07-1.97(\mathrm{~m}, 2 \mathrm{H})$, 1.88-1.85 (m, 2H), 1.77-1.65 (m, 5H), $1.47(\mathrm{~s}$, 1H). ${ }^{13} \mathrm{C}$ NMR $\quad(125 \mathrm{MHz}, \quad$ DMSO-d 6$)$ : $\delta=176.31,162.17,37.61,35.70,34.91,33.99$, $32.48,30.92,27.29,20.98$. Anal. calcd. for $\mathrm{C}_{10} \mathrm{H}_{15} \mathrm{NO}_{3}: \mathrm{C}, 60.90 ; \mathrm{H}, 7.67 ; \mathrm{N}, 7.10$. Found: C, $60.78 ; \mathrm{H}, 7.77 ; \mathrm{N}, 7.02$.

General method of Beckmann rearrangement of anti- and syn-8oximinobicyclo[3.2.1]octane- and 9oximinobicyclo[3.3.1] nonane-3-carboxylic

acids (1.1, 1.2, 2.1, 2.2). Solution of $2 \mathrm{mmol}$ of hydroxylamino acid (compounds 1.1, 1.2, 2.1, 2.2) in trifluoroacetic acid $(20 \mathrm{ml})$ was heated under reflux for $6 \mathrm{~h}$. The reaction was evaporated under reduced pressure and $20 \mathrm{ml}$ of distilled water was added to the residue. Resulting mixture was evaporated under reduced pressure again and $20 \mathrm{ml}$ of distilled water was added to the residue. The product was filtered, washed with water and dried to give compounds 14-19.

syn-6-aza-7-oxobicyclo[3.2.2]nonane-3carboxylic acid (18). Yield of $84 \%$, a white solid, m.p. $218-220{ }^{\circ} \mathrm{C} ;{ }^{1} \mathrm{H}$ NMR $(400 \mathrm{MHz}$, $\left.\mathrm{CD}_{3} \mathrm{OD}\right): \delta=3.55(\mathrm{~s}, 1 \mathrm{H}), 2.83(\mathrm{~s}, 1 \mathrm{H}), 2.42$ (s, $1 \mathrm{H}), 2.03-1.99(\mathrm{~m}, 2 \mathrm{H}), 1.89-1.76(\mathrm{~m}, 4 \mathrm{H})$, 1.63-1.52 (m, 2H). ${ }^{13} \mathrm{C} \mathrm{NMR} \mathrm{(125} \mathrm{MHz,}$ $\left.\mathrm{CD}_{3} \mathrm{OD}\right): \delta=180.93,178.34,48.57,40.36$, 39.84, 37.20, 31.12, 25.12, 22.33. HRMS (CI,
$\left.\mathrm{CH}_{4}\right)$ calcd for $\mathrm{C}_{9} \mathrm{H}_{14} \mathrm{NO}_{3}$ : $184.0974\left(\mathrm{MH}^{+}\right)$; found: 184.0969 .

anti-6-aza-7-oxobicyclo[3.2.2]nonane-3carboxylic acid (14). Yield of $56 \%$, a white solid, m.p. $207-209{ }^{\circ} \mathrm{C} ;{ }^{13} \mathrm{C}$ NMR (125 MHz, $\left.\mathrm{CD}_{3} \mathrm{OD}\right): \delta=180.60, \quad 177.29, \quad 48.02,40.92$, 39.15, 36.23, 32.73, 28.68, 26.74. HRMS (CI, $\left.\mathrm{CH}_{4}\right)$ calcd for $\mathrm{C}_{9} \mathrm{H}_{14} \mathrm{NO}_{3}$ : $184.0974\left(\mathrm{MH}^{+}\right)$; found: 184.0971 .

8-oxo-7-oxabicyclo[4.2.1] nonane-3-carbonitrile (16). Yield of $38 \%$, a colorless oil. ${ }^{13} \mathrm{C}$ NMR (125 MHz, $\left.\mathrm{CD}_{3} \mathrm{OD}\right): \delta=178.55,123.21,80.86$, $39.54,34.65,32.53,30.96,28.34,26.82$. HRMS $\left(\mathrm{CI}, \mathrm{CH}_{4}\right)$ calcd for $\mathrm{C}_{9} \mathrm{H}_{12} \mathrm{NO}_{2}: 166.0868$ $\left(\mathrm{MH}^{+}\right)$; found: 166.0866 .

anti-9-aza-10-oxobicyclo[3.3.2] decane-3carboxylic acid (15). Yield of $85 \%$, a white solid, m.p. $203-205{ }^{\circ} \mathrm{C} ;{ }^{1} \mathrm{H}$ NMR $(400 \mathrm{MHz}$, DMSO- $\mathrm{d}_{6}$ ): $\delta=12.28($ br s, $1 \mathrm{H}, \mathrm{COOH}), 7.60$ (d, $J=6.4 \mathrm{~Hz}, 1 \mathrm{H}, \mathrm{NH}$ ), 3.47 (s, 1H), 3.38 (s, 1H), 2.69 (s, 1H), 2.24 (t, $J=7.2 \mathrm{~Hz}, 1 \mathrm{H}), 2.12$ $2.05(\mathrm{~m}, 2 \mathrm{H}), 1.86-1.80(\mathrm{~m}, 1 \mathrm{H}), 1.68-1.64(\mathrm{~m}$, $1 \mathrm{H}), 1.55-1.41(\mathrm{~m}, 5 \mathrm{H}) .{ }^{13} \mathrm{C} \mathrm{NMR}(125 \mathrm{MHz}$, DMSO-d 6 ): $\delta=176.73,176.18,44.64,42.16$, $39.84,34.44,29.13,27.93,25.10,18.34$. HRMS $\left(\mathrm{CI}, \mathrm{CH}_{4}\right)$ calcd for $\mathrm{C}_{10} \mathrm{H}_{16} \mathrm{NO}_{3}: 198.1130$ $\left(\mathrm{MH}^{+}\right)$; found: 198.1124.

syn-9-aza-10-oxobicyclo[3.3.2]decane-3carboxylic acid (15). Yield of $86 \%$, a white 
solid, m.p. $88-90 \quad{ }^{\circ} \mathrm{C} ;{ }^{1} \mathrm{H}$ NMR $(400 \mathrm{MHz}$, DMSO-d ${ }_{6}$ ): $\delta=12.24$ (br s, $\left.1 \mathrm{H}, \mathrm{COOH}\right), 7.57$ $(\mathrm{d}, J=8.0 \mathrm{~Hz}, 1 \mathrm{H}, \mathrm{NH}), 3.45(\mathrm{~s}, 1 \mathrm{H}), 2.92(\mathrm{t}$, $J=7.4 \mathrm{~Hz}, 1 \mathrm{H}), 2.70-2.60(\mathrm{~m}, 1 \mathrm{H}), 1.96-1.92$ (m, 1H), 1.88-1.68 (m, 4H), 1.64-1.45 (m, 3H), 1.43-1.34 (m, 2H). ${ }^{13} \mathrm{C}$ NMR $\quad(125 \mathrm{MHz}$, DMSO-d 6 ): $\delta=177.09,176.56,44.97,42.64$, 36.93, 36.62, 30.20, 27.72, 23.40, 22.11. HRMS

$\left(\mathrm{CI}, \mathrm{CH}_{4}\right)$ calcd for $\mathrm{C}_{10} \mathrm{H}_{16} \mathrm{NO}_{3}: 198.1130$ $\left(\mathrm{MH}^{+}\right)$; found: 198.1134 .

\section{Reference}

[1] Gawley RE. The Beckmann reactions: rearrangements, elimination-additions, fragmentations and rearrangement-cyclizations. Org. Reactions. New York, John Wiley \& Sons; 1988; v35. - Chapter 1.

[2] Nace HR, Watterson AC. Application of the Beckmann rearrangement to the preparation of $\alpha$ azapregnane derivatives J. Org. Chem. 1966;31(7):21092115 .

[3] Ronchin L, Vavasori A. On the mechanism of the organocatalyzed Beckmann rearrangement of cyclohexanone oxime by trifluoroacetic acid in aprotic solvent. J. Mol. Catal. A-Chem. 2009;313:22-30.

[4] Nishiyama H, Sakuta K, Osaka N, Itoh K. Silicon-directed Beckmann fragmentation. Catalytic cleavage of cyclic \& trimethylsilylketoxime acetates with trimethylsilyl trifluoromethanesulfonate. Tetrahedron Lett. 1983;24(37):4021-4024.

[5] Wolff S, Barany F, Agosta WC. Novel Photochemical Rearrangements of Citral and Related Compounds at Elevated Temperatures. J. Am. Chem. Soc. 1980;102(7):2378-2386.

[6] Narula AS, Sethi SP. Chiral Trans Hydrindenones: Synthesis of Optically Pure [3aaH (S),
7aßMe (S)]-trans-1-methyl-7a-methylhydrindan-1,4diene-6-one. Tetrahedron Lett. 1984;25(6):685-688.

[7] Stevens RV, Gaeta FCA. Camphorae: Chiral Intermediates for the Total Synthesis of Steroids. Tetrahedron. 1985;41(1):93-100.

[8] Tartaggia S, Lucchi O, Gambaro A, Zangrando R, Fabris F, Scarso A. Chiral $\mathrm{M}_{3} \mathrm{~L}_{2}$ SelfAssembled Capsules through Metal Coordination of Enantiopure Ligating Benzocyclotrimers: NMR Spectroscopic and ESI Mass Spectrometric Investigation. Chem. Eur. J. 2013;19(18);5701-5714.

[9] Klinot J, Vystrcil A. Beckmannsche umlagerung von triterpen-3-ketoximen Collect. Czech. Commun. 1962;27(2):377-386.

[10] Blieskorn $\mathrm{CH}$, Hemmer E. Umlagerung von Halogennitrosopinan in 6-Halogencampheroxim. Chem. Ber. 1976;109:1418-1423.

[11] Hill RK, McKinnie BG, Conley RT, Darby PS. Novel products from Beckmann fragmentation of camphor oxime in polyphosphoric acid. Tetrahedron. 1988;44(11);3405-3412.

[12] VerHaeghe DG, Weber GS, Pappalardo PA. Beckmann fregmentation versus Beckmann rearrangement in dehydrocamphor derivatives. Tetrahedron Lett. 1989;30(31):4041-4044.

[13] Hunt PA, Moody CJ. Beckmann rearrangements in the bicyclo[2.2.1]heptan-2-one series. Tetrahedron Lett. 1989;30(51):7233-7234.

[14] Krow GR, Szczepanski S. Unusual regiochemistry in a Beckmann-like rearrangement of camphor. $\alpha$-camphidone via methylene migration. Tetrahedron Lett. 1980;21(48):4593-4596.

[15] Martinez AG, Vilar ET, Fraile AG, de la Moya CS, Maroto BL. Intramolecular-activation evidence for the unexpected Beckmann fragmentation of $\mathrm{C}(1)$ substituted-7-bromonorbornane-2-ones. Tetrahedron. 2004;60(42):9447-9451.

[16] Nelson RP, McEuen JM, Lawton RG. $\alpha, \alpha^{\prime}$ Annulation of cyclic ketones. Synthesis of bicyclo 
[3.2.1] octane derivatives. Journal of Organic Chemistry, 1969;34(5):1225-1229.

[17] Marschall H, Vogel F, Weyerstahl P. Synthesis of $\alpha$-methylene- $\delta$-lactones. Chemische Berichte. 1974;107(9):2852-2859.

[18] Peters JA, Van Der Toorn JM, Van Bekkum H. 3,7-disubstituted bicyclo[3.3.1]nonanes-II. Synthesis and conformation of some 3,7-disubstituted 9oxobicyclo[3.3.1]nonanes. Tetrahedron. 1974;30(5): 633640.

[19] Armarego WLF, Chai C. Purification of Laboratory Chemicals, 5th Edition; BultesworthHeinemann: Oxford, 2003. 